\title{
ANALISIS GAMEPLAY GAME GENRE VIRTUAL PET
}

\author{
Abi Senoprabowo \\ Program Studi Desain Komunikasi Visual \\ Fakultas Ilmu Komputer, Universitas Dian Nuswantoro Semarang \\ abiseno.p@gmail.com
}

\begin{abstract}
Abstrak
Game adalah struktur interaktif yang membuat pemain berjuang menuju sebuah tujuan. Game dapat memberikan emosi dan mood, menghubungkan dengan orang latihan, sarana latihan, serta dapat memberikan edukasi. Salah satu game yang berkembang saat ini adalah game bergenre Virtual pet. Game virtual pet merupakan game simulasi memelihara sesuatu. Virtual pet memiliki gameplay yang menarik dan menyenangkan yang membuat pemain seolah-olah benar-benar memiliki binatang peliharaan mereka sendiri. Virtual pet dianggap oleh sebagian besar penggunanya dapat memberikan kegembiraan serta rasa kasih sayang karena tingkat interaksinya yang baik. Banyak pengembang game pemula yang mengembangkan genre ini sebagai game yang mereka buat karena kemudahaan dan tingkat penggunanya yang banyak. Akan tetapi banyak dari pengembang game pemula tidak memperhatikan tingkat keberlanjutan game virtual pet yang mereka buat sehingga membuat pemain cepat bosan. Pada penelitian ini, analisis game bergenre virtual pet yang sudah sukses dibuat seperti Zombigotchi, Tamagotchi Unicorn, dan Bird Land, diharapkan dapat membantu para pengembang game pemula agar mengetahui cara merancang dan mengembangkan game virtual pet dengan baik.
\end{abstract}

Kata Kunci: game, gameplay, virtual pet

\section{PENDAHULUAN}

Dalam kamus bahasa Indonesia Game diartikan sebagai permainan [1]. Game adalah sesuatu yang anda mainkan (Schell, 2008). Game berbeda dengan mainan (toy). Mainan adalah sebuah objek yang kita mainkan. Namun permainan dan mainan samasama harus memiliki unsur kesenangan (fun). Sedang bermain adalah kegiatan apapun yang kita lakukan secara spontan dan untuk diri sendiri (Santayana dalam Schell, 2008). Sehingga makna keseluruhan dari game adalah struktur interaktif yang membuat pemain berjuang menuju sebuah tujuan (Costikyan dalam Schell, 2008) [2].

Berdasarkan prediksi Applift dan Newzoo, pasar mobile game di tingkat global akan meningkat pesat seiring dengan pertumbuhan smartphone (Viva News, diakses 6 November 2014). Indonesia memiliki potensi yang cukup besar bagi para pengembang game mobile. Untuk Indonesia, menurut data dari Frost \& Sullivan, 80 dari 100 orang memiliki smartphone pada 2013. Secara tidak langsung, penetrasi smartphone dari 9 persen pada 2012 akan meningkat 50 persen pada 2015 (Viva News, diakses 6 November 2014) [3].

Sekarang, game berbentuk virtual pet sangat berkembang. Banyak pembuat game yang menggunakan genre ini karena tingkat memainkannya sangat mudah tetapi sangat menyenangkan. Own Pet Dragon adalah salah satu game bergenre virtual pet 
yang berhasil memenangkan game terbaik INAICTA 2013 [4]. Own Pet Dragon memiliki fitur-fitur yang menarik untuk dimainkan pengguna sehingga membuat juri memilihnya sebagai pemenang. Karena fitur yang menarik pemain dan mudah untuk dibuat, game bergenre ini menjadi salah satu game favorit para pengembang game sebagai game yang mereka kembangkan.

Virtual pet atau Hewan peliharaan virtual, saat ini sangat dikomersialisasikan sebagai salah satu bentuk hiburan. Virtual pet terbagi menjadi dua kategori utama yaitu yang bentuk fisik dan yang berentuk aplikasi perangkat lunak. Virtual pet dalam bentuk aplikasi perangkat lunak adalah salah satu jenis game yang termasuk dalam genre simulasi. Virtual pet dianggap oleh sebagian besar pengguna dapat memberikan kegembiraan serta rasa kasih sayang karena tingkat interaksinya yang baik. Pengaruh Virtual pet dalam kehidupan menurut Danauta (2012) meliputi pendidikan, kesehatan, serta reaksi sosial dan psikologis bagi pengguna dari berbagai usia [5].

Virtual pet mulai populer di seluruh dunia pada akhir 1990-an ketika Jepang mainan produsen Bandai merilis Tamagotchi [6]. Tamagotchi memiliki ciri khas berbentuk gantungan kunci, memiliki layar hitam putih kecil, hanya terdiri dari tiga tombol, dapat mengelurakan suara, memiliki sensor gerak, serta memiliki mikrofon. Pengguna mainan ini dapat memberi makan, membersihkan dan bermain dengan Tamagotchi mereka. Hewan peliharaan ini akan berkembang dari waktu ke waktu ketika dimainkan. Dengan Gameplay seperti ini jelas membuat banyak pengguna menjadi sangat mencintai hewan peliharaan mereka, bahkan banyak yang berkabung ketika hewan peliharaannya mati.

\section{TINJAUAN PUSTAKA}

\subsection{Game}

Game adalah sesuatu hal yang sangat manusiawi dan memberikan efek kesenangan. Tetapi banyak orang memiliki pandangan negatif bahwa game itu berbahaya. Padahal secara langsung maupun tidak langsung, game memiliki beberapa manfaat. Berikut adalah beberapa manfaat game menurut Schell (2008) [2]:

1. Memelihara emosi dan mood, dengan bermain game kita dapat menyalurkan dan membuat emosi baru. Contohnya adalah penyaluran marah dan frustasi. Dengan game kita dapat menyalurkan emosi dalam dunia yang aman. Game juga dapat membuat mood kita menjadi ceria. Game juga dapat menjauhkan kita dari masalah yang ada dalam dunia nyata, walaupun hanya sementara. Game juga dapat membuat kita lebih percaya diri. Dan yang terpenting, game dapat membuat kita relaks.

2. Menghubungkan, game secara tidak langsung dapat menghubungkan kita pada orang lain. Ketida mendapat kesukaan yang sama atau mendapat hambatan dalam memainkan sebuah game, maka kita akan bertemu dengan orang lain yang memiliki kesukaan yang sama tersebut. Game juga dapat mengisi aktifitas pertemuan sebuah kelompok masyarakat. Bahkan orang dapat dengan sengaja berkumpul untuk memainkan sebuah game. 
3. Latihan, game juga dapat melatih kita baik secara mental maupun fisik. Pemecahan masalah pada game serta kecepatan maupun ketangkasan dalam memainkan game dapat menjadi sarana latihan mental. Untuk game tertentu, game juga bisa melatih secara fisik, terutama untuk game-game simulasi yang mengunakan teknologi yang memungkinkan interaksi dengan game dengan basis gerakan.

4. Edukasi, selama ini belajar terkesan serius. Tetapi game secara tidak langsung sistem dalam game adalah edukasi. Siswa (pemain) diberi serangkaian tugas (tujuan) yang harus diselesaikan (dicapai) sesuai waktu yang ditentukan (batas waktu). Mereka menerima nilai (skor) sebagai umpan balik jika sudah menyelesaikan tugas (tantangan) sehingga mereka akan berusaha lebih keras, sampai akhirnya mereka dihadapkan dengan ujian akhir (raksasa bos), yang mereka hanya bisa melewati (kekalahan) jika mereka telah menguasai semua keterampilan dalam game (permainan). Siswa (pemain) yang melakukan dengan baik akan tercantum dalam daftar kehormatan (Rangking).

\subsection{Virtual Pet}

Virtual pet atau Hewan peliharaan virtual, saat ini sangat dikomersialisasikan sebagai salah satu bentuk hiburan . Virtual pet terbagi menjadi dua kategori utama yaitu yang bentuk fisik dan yang berentuk aplikasi perangkat lunak (Danauta, 2012) [5]. Virtual pet dalam bentuk aplikasi perangkat lunak merupakan salah satu jenis game ber-genre simulasi. Virtual pet dianggap oleh sebagian besar penggunanya dapat memberikan kegembiraan serta rasa kasih sayang karena tingkat interaksinya yang baik.

Virtual pet mulai populer di seluruh dunia pada akhir 1990-an ketika produsen mainan Jepang, Bandai merilis Tamagotchi [6]. Tamagotchi memiliki ciri khas berbentuk gantungan kunci, memiliki layar hitam putih kecil, hanya terdiri dari tiga tombol, dapat mengelurakan suara, memiliki sensor gerak, serta memiliki mikrofon. Pengguna mainan ini dapat memberi makan, membersihkan dan bermain dengan Tamagotchi mereka. Hewan peliharaan ini akan berkembang dari waktu ke waktu ketika dimainkan.

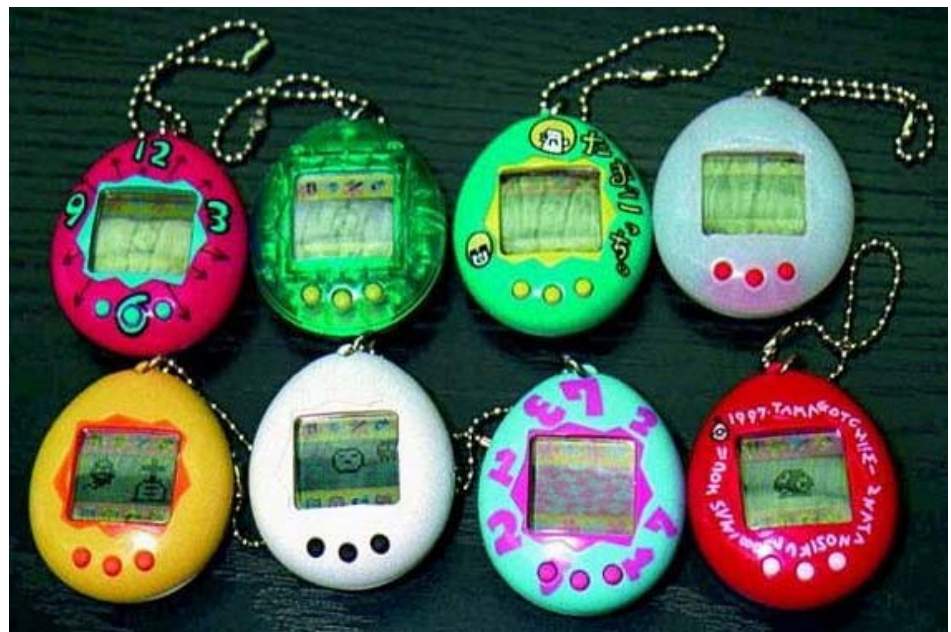

Gambar 2. Berbagai bentuk Tamagochi yang dikeluarkan Bandai [Sumber: http://www.telegraph.co.uk/technology/news/9857086/ Tamagotchi-to-return-as-iPhone-and-Android-app.htm/] 
Virtual pet lalu berkembang ke arah aplikasi piranti lunak. Game virtual pet memiliki salah satu ciri yang mendasar yaitu kurang pastinya ukuran menang atau kalah dalam permainan. Aplikasi virtual pet terbagi menjadi 2 golongan besar, yaitu Web-based digital pets dan Software-based digital pets [7]. Web-based digital pets atau digital per berbasis web atau website adalah hewan peliharaan virtual yang dapat diakses dengan cara membuka website yang menyediakan hewan peliharaan virtual. Karena berbasis website, maka untuk memainkan aplikasi ini, pemain harus terkoneksi dengan internet. Website yang menyediakan hewan peliharaan virtual, biasanya gratis dan dapat diakses oleh semua orang yang mendaftar. Website ini dapat diakses melalui web browser yang dimiliki komputer kita. Dalam permainan ini, pemain dapat bermain game untuk mendapatkan uang virtual, yang kemudian dibelanjakan untuk barangbarang atau makanan untuk hewan peliharaannya. Beberapa website dapat menampilkan hewan peliharaan anda pada halaman website anda sendiri. Beberapa website ada yang mewajibkan pemain membayar uang untuk dapat mengadopsi hewan peliharaan virtual. Ada beberapa website yang menerapkan sistem pembibitan, yaitu pemain lain dapat memelihara hewan peliharaan virtual jika ada pemain lain yang hewan peliharaannya telah melahirkan. Salah satu website populer permainan hewan peliharaan virtual adalah clubpenguin.com dan neopets.com.

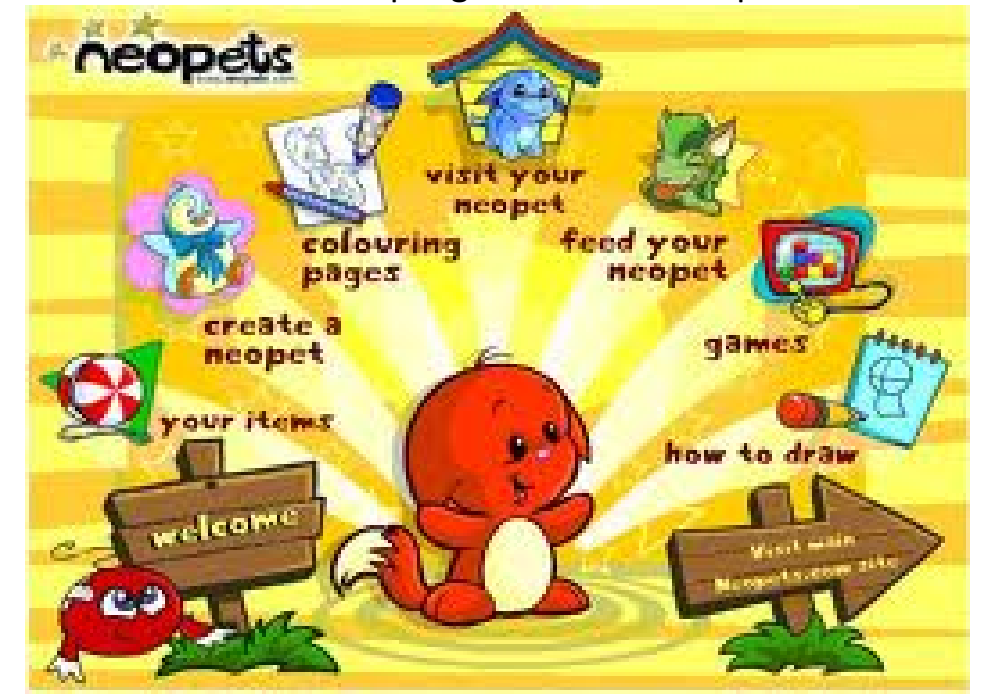

Gambar 3. Neopets.com contoh hewan peliharaan virtual berbasis website [Sumber: http://www.pinkpt.com/neodex/index.php/Neopets_Jr.]

Untuk Software-based digital pets adalah hewan peliharaan virtual berbasis aplikasi. Berbeda dengan hewan peliharaan virtual berbasis website, permainan ini tidak harus tersambung dengan internet. Ada banyak video game yang berfokus pada perawatan hewan peliharaan virtual. Game tersebut termasuk sebagai sub-kelas dari game simulasi. Karena daya komputasi yang lebih baik dibandingkan dengan hewan peliharaan berbasis web, game virtual pet berbasis software biasanya dapat dibuat dengan tingkat visual yang lebih tinggi dan interaktivitas yang lebih baik pula. 

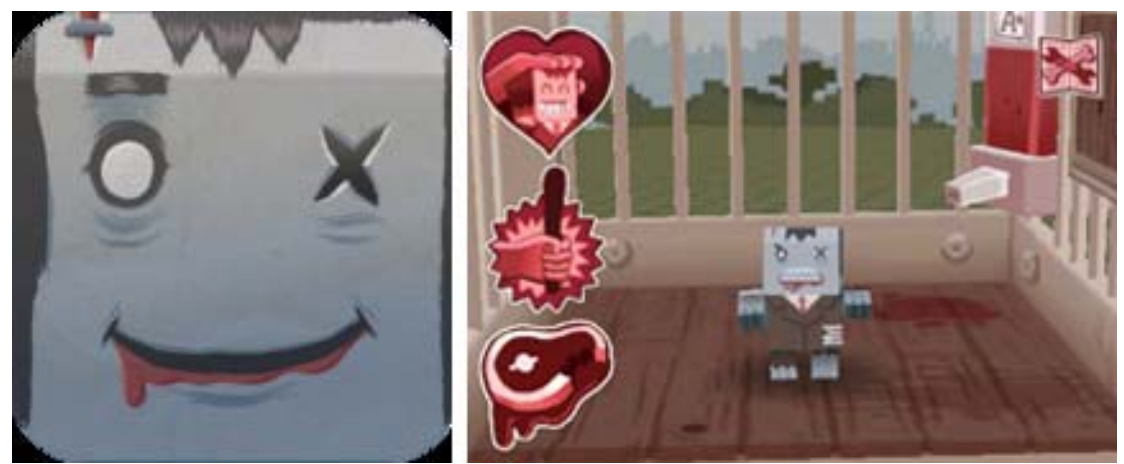

Gambar 4. Zombigotchi contoh hewan peliharaan virtual berbasis software [Sumber : http://ncrpc.blogspot.com/2010_11_01_archive.htm/]

Sedang untuk software-based digital pets adalah hewan peliharaan virtual berbasis aplikasi. Berbeda dengan hewan peliharaan virtual berbasis website, permainan ini tidak harus tersambung dengan internet. Ada banyak video game yang berfokus pada perawatan hewan peliharaan virtual. Game tersebut termasuk sebagai sub-kelas dari game simulasi. Karena daya komputasi yang lebih baik dibandingkan dengan hewan

\section{METODE DAN PEMBAHASAN}

\subsection{Metode}

Metode yang digunakan untuk membedah gameplay game bergenre Virtual pet menggunakan teori elemen-elemen game Fullerton. Elemen-elemen dalam perancangan sebuah game menurut Fullerton (2008) terbagi menjadi dua kelompok besar yaitu elemen formal dan elemen dramatis [8]. Elemen formal game adalah elemen dasar yang membentuk sebuah game. Berikut adalah yang termasuk elemen formal game,

\section{Pemain}

Pemain menjadi elemen utama dalam sebuah game karena pemain adalah yang memainkan game tersebut. Merancang keterlibatan pemain dalam game adalah hal penting. Pemain yang merasa terlibat dalam gam tersebut, akan membuat pemain betah memainkan game tersebut. Hal yang perlu ditentukan pada elemen pemain ini adalah berapa pemain yang dibutuhkan, berapa total pemain yang dapat bermain, apa peran masing-masing pemain, dan bagaimana hubungan antar pemain.

2. Tujuan

Tujuan sebuah game menjadi alasan awal pemain untuk memainkan game tersebut. Tujuan dari sebuah adalah sesuatu yang akan dicapai pemain dalam memainkan game tersebut. Tujuan tersebut harus bisa dicapai. Dalam mencapai tujuan tersebut haruslah memiliki tantangan serta hambatan untuk mencapainya.

3. Prosedur

Prosedur adalah metode atau kombinasi cara yang digunakan oleh pemain dalam sebuah game untuk mencapai tujuan game tersebut. Prosedur ini berisi bagaimana menjalankan karakter dalam game, bagaimana melompat, bagaimana untuk jalan, bagaimana untuk mengambil sesuatu, dan lain sebagainya. 
4. Aturan

Aturan berisi hal-hal yang dapat dilakukan oleh pemain dalam sebuah game. Aturan sangat penting dalam sebuah game. Aturan yang jelas dapat mengarahkan pemain dan meningkatkan kenyamanan pemain dalam bermain game tersebut. Dengan aturan ini, pemain tidak akan kebingungan dalam mencapai tujuan game tersebut.

5. Sumber Daya

Sumber daya merupakan aset atau sesuatu yang ada dalam game. Aset ini berupa item-item yang dapat digunakan oleh pemain untuk mencapai tujuan. Sumber daya yang ada dapat membantu pemain, tetapi juga dapat menjatuhkan pemain. Dua sifat yang harus dimiliki oleh sumber daya adalah kebutuhan dan kelangkaan.

6. Konflik

Konflik adalah hal yang sangat penting. Konflik menjadikan game tidak berjalan dengan datar. Kemuncul konflik dalam game dapat dilakukan ketika pemain mencoba untuk menyelesaikan tujuan game dalam aturan-aturan serta keterbatasan pemain dalam menjalankan karakter dalam game. Konflik dirancang dengan memadukan aturan-aturan, batasan dan prosedur sehingga pemain akan merasa dilema dalam mencapai tujuan game tersebut.

7. Batasan

Batasan adalah sesuatu yang menghalangi pemain untuk keluar dari permainan. Batasan ini dapat berupa fisik seperti arena atau dunia dari game tersebut. Batasan juga dapat berupa konsep seperti jalan cerita pada sebuah game yang telah ditentukan sebelumnya.

8. Hasil dan akibat

Hasil dan akibat merupakan sesuatu yang dapat diukur yang diperoleh setelah usaha pemain untuk mencapai tujuan game. Hasil dapat bersifat konkret, artinya dapat dilihat secara fisik, jelas. Hasil dapat bersifat abstrak, artinya berupa suatu pencapaian terhadap suatu keadaan.

\subsection{Pembahasan}

Game yang dijadikan sampel untuk membedah gameplay game bergenre Virtual pet adalah Zombigotchi (android, ios) [9], Tamagotchi Unicorn (android, ios) [10], \& Bird Land 2.0 (PC) [11]. Ketiga game ini mewakili berbagai paltform yang banyak digunakan sekarang ini. Hal ini dimaksudkan untuk mendapatkan perbandingan yang dapat mewakili semua jenis game virtual pet. Berikut adalah pembahasannya,

1. Pemain

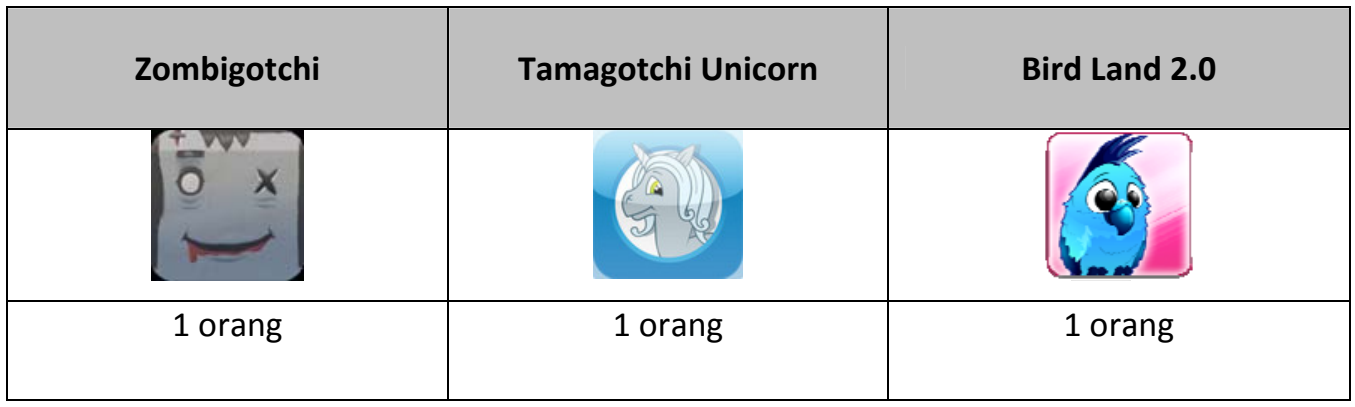

Untuk jenis game dengan genre virtual pet biasanya diperuntukan untuk 1 pemain saja. 
2. Tujuan

\begin{tabular}{|c|c|c|}
\hline Zombigotchi & Tamagotchi Unicorn & Bird Land 2.0 \\
\hline $\begin{array}{c}\text { Memelihara sebuah } \\
\text { zombie }\end{array}$ & $\begin{array}{c}\text { Memelihara sebuah } \\
\text { unicorn }\end{array}$ & Memelihara sebuah burung \\
\hline
\end{tabular}

Pada permainan berbasis Virtual pet, biasanya dikhususkan untuk memelihara 1 jenis binatang saja. Hal ini dimaksudkan untuk mensimulasikan bahwa 1 gadget adalah 1 kandang. Sesuatu yang dipelihara itu pasti sesuatu yang disenangi oleh pemainnya.

3. Prosedur

\begin{tabular}{|c|c|c|}
\hline Zombigotchi & Tamagotchi Unicorn & Bird Land 2.0 \\
\hline $\begin{array}{c}\text { Pada saat memainkan } \\
\text { permainan ini, pemain } \\
\text { langsung diberikan sebuah } \\
\text { zombie untuk dipelihara. } \\
\text { Ada } 5 \text { karakter yang dapat } \\
\text { dipilih dan beberapa } \\
\text { karakter yang masih } \\
\text { terkunci. }\end{array}$ & $\begin{array}{c}\text { Pada permaianan ini, } \\
\text { pemain diberikan sebuah } \\
\text { unicorn untuk dipelihara. } \\
\text { Unicorn adalah binatang } \\
\text { imajiner yang ada di Eropa. } \\
\text { Pemain akan diberikan } 2 \\
\text { buah pilihan, yaitu unicorn } \\
\text { jantan atau unicorn betina. }\end{array}$ & $\begin{array}{l}\text { Pemain akan diberikan } \\
\text { sebuah kandang burung } \\
\text { (lebih tepatnya habitat). } \\
\text { Pada kandang ini pemain } \\
\text { dapat memelihara berbagai } \\
\text { jenis burung. Ada berbagai } \\
\text { jenis burung, tergantung dari } \\
\text { versi yang pemain mainkan. }\end{array}$ \\
\hline
\end{tabular}

Pada permainan berbasis Virtual pet, pemaian diberikan sebuah binatang peliharaan. Ada yang bisa memelihara beberapa binatang dalam 1 kandang seperti Bird Land. Wajar memelihara burung dalam 1 kandang karena burung ukurannya kecil. Sedang untuk binatang yang ukurannya besar seperti Unicorn dan Zombie, wajarnya 1 kandang untuk 1 binatang. Disini pemain diberikan keleluasan untuk memilih jenis karakter untuk dipelihara. Pada unicorn, pemain hanya diberikan pilihan antara unicorn jantan dan betina. Tetapi jenis karakter tidak berpengaruh pada permainan.

4. Aturan

\begin{tabular}{|c|c|c|}
\hline Zombigotchi & Tamagotchi Unicorn & Bird Land 2.0 \\
\hline $\begin{array}{c}\text { Pemain memelihara } \\
\text { zombie langsung dewasa. } \\
\text { Tidak dari bayi. Pada game } \\
\text { ini, pemain harus membuat } \\
\text { mood zombie baik, yaitu } \\
\text { dengan memberinya } \\
\text { makan, melatihnya, dan } \\
\text { menyayanginya. Dalam } 1 \\
\text { kandang, pemain hanya } \\
\text { memainkan } 1 \text { zombie, } \\
\text { tetapi dalam game ini }\end{array}$ & $\begin{array}{l}\text { Walaupun memilih } \\
\text { karakternya hanya terbatas } \\
\text { pada jenis kelaminnya saja, } \\
\text { tetapi game ini lebih detail } \\
\text { dalam memelihara } \\
\text { binatang peliharaannya. } \\
\text { Kalori dari makanan yang } \\
\text { dibutuhkan oleh si unicorn } \\
\text { harus dijaga. Nilai kalori } \\
\text { antara 0-34560. Unicorn } \\
\text { bisa mati kalau kelaparan }\end{array}$ & $\begin{array}{l}\text { Pertama-tama dalam } \\
\text { permain ini, pemain harus } \\
\text { membeli bayi burung di } \\
\text { toko. Kemudian membeli } \\
\text { barang untuk menghias } \\
\text { kandangnya. Tentu saja } \\
\text { setelah itu pemain perlu } \\
\text { menjaga mereka. dan itulah } \\
\text { sebabnya pemain dapat } \\
\text { menggelitik mereka untuk } \\
\text { membuat mereka bahagia }\end{array}$ \\
\hline
\end{tabular}




\begin{tabular}{|c|c|c|}
\hline pemain diijinkan memiliki & atau obesitas. Jadi pemain & dan memastikan bahwa \\
banyak kandang. Pada awal & harus mengkontrol antara & mereka memiliki cukup \\
permainan hanya ada 5 & makan dan aktifitas & makanan. Jika pemain \\
karakter yang terbuka. Ada & fisiknya. Dalam permainan & menjaganya dengan baik, \\
beberapa karakter yang & ini ada sebuah toko untuk & burung akan tumbuh \\
masih terkunci. Pada game & membeli makanan dan & menjadi dewasa. Selain itu, \\
ini, ada 2 buah mini game. & alat-alat untuk aktifitas si & dengan mengklik burung \\
Untuk membuka karakter & Unicorn. Uang yang & dengan alat berkembang \\
yang masih terkunci, & digunakan adalah mata & biak, burung dapat \\
pemain harus memainkan & uang yang ada di game. & berkembang biak. \\
mini game ini. & Pemain harus membeli & \\
& uang ini agar bisa membeli & \\
\hline & di toko tersebut. & \\
\hline
\end{tabular}

Inti permainan yang berbasis virtual pet adalah pemain memelihara layaknya itu peliharaan sungguhan. Pemain harus memberi makan, merawat, melatih, dan memberi perhatian. Yang membedakan adalah detail pemeliharaan itu. Pada Unicorn sangat detail. Pemain harus memperhatikan jumlah makanan dengan aktifitas peliharaan. Jarang ada virtual pet yang mati karena terlalu banyak dikasih makan. Yang membedakan lagi adalah kelangsungan hidup. Pada zombigotchi tidak ada. Pada unicorn ada, dan pada Bird land, malah bisa berkembang biak.

5. Sumber Daya

\begin{tabular}{|c|c|c|}
\hline Zombigotchi & Tamagotchi Unicorn & Bird Land 2.0 \\
\hline $\begin{array}{c}\text { Zombigotchi memiliki fitur - } \\
\text { fitur lucu interaksi dengan } \\
\text { binatang peliharan seperti } \\
\text { memberi makan, memberi } \\
\text { kasih sayang, dan } \\
\text { memberikan kekerasan / } \\
\text { menghajar. Makanan yang } \\
\text { diberikan seperti darah, } \\
\text { daging segar, daging } \\
\text { kaleng. Kasih sayang } \\
\text { seperti memarut dengan } \\
\text { parutan, memberi boneka, } \\
\text { memberi bunga. } \\
\text { Menghajar seperti } \\
\text { memukul dengan tongkat } \\
\text { dan membelahnya dengan } \\
\text { laser. } \\
\text { Zombigotchi juga memiliki } \\
\text { fitur untuk mendandani } \\
\text { zombi mereka menjadi } \\
\text { dokter, pekerja kantoran, } \\
\text { dll. Zombigotchi juga } \\
\text { memiliki fitur mini game. }\end{array}$ & $\begin{array}{l}\text { Item yang ada dalam game } \\
\text { ini hampir sama dengan } \\
\text { vitrual pet yang lain seperti } \\
\text { berbagai makanan \& } \\
\text { aksesoris. Item tersebut } \\
\text { dapat dibeli dengan uang } \\
\text { yang disebut stellars. } \\
\text { Stellars didapat dengan } \\
\text { cara melakukan perawatan } \\
\text { unicorn seperti mengajak } \\
\text { bermain \& membersihkan } \\
\text { kotoran. Game ini memiliki } \\
\text { penanda kebutuhan kalori } \\
\text { \& tingkat kebahagiaan. } \\
\text { Pemain dapat } \\
\text { menormalkan kalori \& } \\
\text { kebahagiaan dengan } \\
\text { membeli healing tablet. }\end{array}$ & $\begin{array}{c}\text { Bird Land tidak hanya } \\
\text { memelihara } 1 \text { jenis burung } \\
\text { saja tapi banyak jenis burung } \\
\text { yang bisa dipelihara. Burung } \\
\text { tersebut dapat dibeli. } \\
\text { Pemain juga dapat membeli } \\
\text { kandang dan aksesoris. } \\
\text { Pemain membeli barang } \\
\text { tersebut dengan cara } \\
\text { menjual burung yang sudah } \\
\text { besar. Agar burung dapat } \\
\text { berkembang biak, pemain } \\
\text { harus memberi makan dan } \\
\text { menyentuhnya agar bahagia. } \\
\text { Game ini juga memiliki } \\
\text { Quest atau tugas yang } \\
\text { apabila bisa diselesaikan, } \\
\text { pemain mendapat uang. }\end{array}$ \\
\hline
\end{tabular}


Zombigotchi memiliki sumber daya paling sedikit dan tidak variatif. Pemain akan cepat bosan dan game ini tidak akan dimainkan dalam jangka waktu yang lama karena game ini memang lebih menguatkan pada animasi tingkah zombie yang lucu. Unicorn memiliki sumber daya yang paling baik. Pemain akan memiliki pengalaman seperti memelihara binatang peliharaan sungguhan. Bird land memiliki fitur memelihara standar virtual pet seperti zombigotchi. Akan tetapi Bird Land memiliki fitur-fitur yang lebih banyak dibanding zombigotchi sehingga pemain akan dapat memainkannya dalam waktu lebih lama.

6. Konflik

\begin{tabular}{|c|c|c|}
\hline Zombigotchi & Tamagotchi Unicorn & Bird Land 2.0 \\
\hline $\begin{array}{l}\text { Konflik yang terjadi hanya } \\
\text { ketika ingin membuka } \\
\text { karakter yang lain, yaitu } \\
\text { dengan memainkan mini } \\
\text { games yang ada. Tiap } \\
\text { karakter memiliki gaya } \\
\text { yang berbeda-beda. }\end{array}$ & $\begin{array}{c}\text { Konflik yang terjadi yaitu } \\
\text { ketika anda harus } \\
\text { memperhitungkan apa } \\
\text { yang harus anda berikan } \\
\text { pada unicorn. Kalau } \\
\text { pemain tidak } \\
\text { memperhitungkannya, } \\
\text { maka unicorn akan mati. } \\
\text { Jumlah dan jenis makanan } \\
\text { harus tepat. Jenis dan } \\
\text { jumlah aktifitas juga harus } \\
\text { tepat. Celakanya pemain } \\
\text { harus membelinya dengan } \\
\text { uang. }\end{array}$ & $\begin{array}{l}\text { Konflik terjadi pada saat } \\
\text { pemain harus menghias } \\
\text { kandang agar burung } \\
\text { senang. Konflik yang kedua } \\
\text { adalah ketika si burung } \\
\text { berkembang biak menjadi } \\
\text { banyak. Pemain akan repot } \\
\text { mengurusnya. }\end{array}$ \\
\hline
\end{tabular}

Unicorn lebih banyak konfliknya karena detail aturan dalam memelihara peliharaan. Bird land standard memelihara binatang pelihaaan tetapi ada konflik ketika burung yang ada menjadi banyak. Sedang zombiegotchi kurang konflik, karena si zombie tidak dapat berkembang. Pemain hanya disuguhkan tingkah laku zombie yang lucu.

7. Batasan

\begin{tabular}{|c|c|c|}
\hline Zombigotchi & Tamagotchi Unicorn & Bird Land 2.0 \\
\hline $\begin{array}{c}\text { Zombigotchi dibatasi } \\
\text { dengan hanya membuka } \\
\text { beberapa karakter diawal } \\
\text { permainan. Pemain harus } \\
\text { membukanya dengan cara } \\
\text { memainkan mini game. } \\
\text { Game ini tidak dibatasi } \\
\text { umur binatang peliharaan. }\end{array}$ & $\begin{array}{c}\text { Tamagotchi Unicorn } \\
\text { dibatasi oleh tingkat kalori } \\
\text { \& kebahagiaan yang dapat } \\
\text { membuat binatang } \\
\text { peliharaan mati. }\end{array}$ & $\begin{array}{l}\text { Bird Land dibatasi oleh } \\
\text { keterbatasan kapasitas } \\
\text { kandang. Game ini juga } \\
\text { dibatasi oleh kebahagian \& } \\
\text { kelaparan. Pemain juga } \\
\text { dibatasi bahwa burung } \\
\text { bertelur jika sepasang jantan } \\
\text { \& betina. }\end{array}$ \\
\hline
\end{tabular}

Batasan Zombigotchi masih sangat luas, sehingga konflik yang ditimbulkan menjadi kurang. Pemain dibebaskan memain tanpa batasan waktu dan keadaan. Sedang Tamagotchi Unicorn memiliki batasan yang sangat kompleks yang membuat pemain mendapat pengalaman yang hampir sama dengan memelihara binatang peliharaan 
sesungguhnya. Bird Land dibatasi oleh kapasitas kandang sehingga ketika pemain ingin mengoleksi banyak burung, mereka harus membeli kandang baru.

8. Hasil dan akibat

\begin{tabular}{|c|c|c|}
\hline Zombigotchi & Tamagotchi Unicorn & Bird Land 2.0 \\
\hline $\begin{array}{c}\text { Membuka karakter yang } \\
\text { terkunci agar dapat melihat } \\
\text { berbagai jenis zombie yang } \\
\text { ada serta melihat reaksi } \\
\text { lucu dari berbagai zombie } \\
\text { yang ada. }\end{array}$ & $\begin{array}{c}\text { Mempertahankan unicorn } \\
\text { agar tetap hidup. }\end{array}$ & $\begin{array}{c}\text { Mempertahankan burung } \\
\text { agar tetap hidup dan } \\
\text { membuatnya menjadi } \\
\text { banyak. }\end{array}$ \\
\hline
\end{tabular}

Permaianan yang berbasis virtual pet, pasti memiliki tujuan agar peliharaan pemain tetap hidup. Terlihat pada Unicorn dan Bird land. Tetapi pada zombigotchi terlihat lebih simpel karena si zombie tetap bisa hidup tanpa perlu pemain apa-apakan.

\section{KESIMPULAN}

\begin{tabular}{|c|c|c|}
\hline Zombigotchi & Tamagotchi Unicorn & Bird Land 2.0 \\
\hline $\begin{array}{l}\text { Zombigotchi terlalu } \\
\text { sederhana untuk dimainkan } \\
\text { dalam jangka waktu yang } \\
\text { panajng. Permainan ini hany } \\
\text { menyediakan beberapa efek } \\
\text { tertawa dan senang dari } \\
\text { pemain, setelah itu akan } \\
\text { membosankan karena } \\
\text { animasi yang ada berulang- } \\
\text { ulang. Aplikasi ini dirancang } \\
\text { dengan baik, tapi tidak } \\
\text { menawarkan insentif untuk } \\
\text { menggunakannya beberapa } \\
\text { kali seperti aspek ukuran dan } \\
\text { penuaan. }\end{array}$ & $\begin{array}{l}\text { Unicorn sangat kompleks } \\
\text { untuk sebuah permainan } \\
\text { yang berbasis virtual pet. } \\
\text { Pemain seperti benar-benar } \\
\text { memelihara peliharaan. } \\
\text { Peliharaan bisa mati karena } \\
\text { kekurangan makanan atau } \\
\text { kelebihan makananan. } \\
\text { Unicorn juga tumbuh dan } \\
\text { menua. Sayangnya dalam } \\
\text { game ini banyak fitur yang } \\
\text { harus dibeli dengan uang. } \\
\text { Permainannya dapat } \\
\text { didownload dengan gratis, } \\
\text { tetapi untuk mendapatkan } \\
\text { beberapa fitur yang ada } \\
\text { didalamnya harus bayar. }\end{array}$ & $\begin{array}{c}\text { Bird land sudah cukup } \\
\text { menarik. Tetapi juga akan } \\
\text { cepat membosankan. Karena } \\
\text { pemain kurang bisa } \\
\text { mendapatkan feel dalam } \\
\text { memelihara peliharaan. } \\
\text { Pemain hanya memberi } \\
\text { makan dan menyayangi } \\
\text { binatang tersebut. Jika sudah } \\
\text { melakukan hal itu, tidak ada } \\
\text { fitur tambahan selanjutnya. } \\
\text { Tetapi untuk permainan } \\
\text { manajemen dalam } \\
\text { memelihara peliharaan, } \\
\text { permainan ini sangat baik. }\end{array}$ \\
\hline
\end{tabular}

Untuk membuat game yang berbasis Virtual pet, sebaiknya pemain mencontoh Unicorn. Karena jika pemain memainkan Unicorn, maka pemain benar-benar akan merasakan seperti benar-benar memelihara peliharaan. Peliharaan bisa mati karena ada berbagai macam sebab. Peliharaan juga bisa tumbuh dan menua. Tapi inti dari permainan virtual pet adalah memberi makan, melatih, memberi perhatian, serta memberikan reaksi yang ditimbulkannya. Tetapi tidak lupa harus ada beberapa fitur yang membuat pemain tidak cepat bosan sehingga pemain dapat memainkan game ini dalam jangka waktu yang lama. 


\section{DAFTAR PUSTAKA}

[1] Depdiknas, 2008. Kamus Besar Bahasa Indonesia. Jakarta: Pusat Bahasa

[2] Schell, J., 2008. The Art of Game Design : A Book of Lenses. Burlington : Morgan Kaufmann.

[3]http://teknologi.news.viva.co.id/news/read/555627-kingsoft-rebut-pasar-gameindonesia-dengan-geo-pet-saga (diakses: 6 November 2014)

[4]http://www.duniaku.net/2013/09/04/mengenal-lebih-dekat-own-pet-dragonjawara-kategori-games-dalam-inaicta-2013/ (diakses: 6 November 2014)

[5] Danauta, C. M., 2012. Virtual pets : Interaction, Uses, Technology. In : Fakultas Pascasarjana Ilmu Elektronika dan Komputer University of Southampton, Interactive Multimedia Systems Conference 2012. Southampton, Inggris.

[6] Allison, A., 2004. Cuteness As Japan's Millennial Product, dalam Tobin, J. (ed.) Pikachu's Global Adventure: The Rise and Fall of Pokémon (h. 34-49). Durham : Duke University Press.

[7] Lawson, S. \& Chesney, T., 2007. The Impact of Owner Age on Companionship with Virtual pets. In : Conference of the European Colloid and Interface Society 2007. Jenewa, Swiss.

[8] Fullerton, T., 2008. Game Design Workshop : A Playcentric Approach to Creating Innovative Games. Burlington : Morgan Kaufmann. 
Andharupa, Jurnal Desain Komunikasi Visual \& Multimedia. Vol.01 No.01 Tahun 2015 